\title{
Gestão das perdas de água e energia em sistema de abastecimento de água da Embasa: um estudo dos fatores intervenientes na RMS
}

\author{
Management of water and energy losses in Embasa \\ water supply systems: a study of factors involved in RMS
}

\section{Renavan Andrade Sobrinho', Patrícia Campos Borja²}

\begin{abstract}
RESUMO
No Brasil, os sistemas de abastecimento de água ainda apresentam perdas de água e baixa eficiência energética. O presente trabalho objetiva analisar os fatores que têm influenciado na efetividade da gestão das perdas de água e energia em sistemas de abastecimento operados pela Empresa Baiana de Águas e Saneamento (Embasa) na região metropolitana de Salvador (RMS). A pesquisa documental e a avaliação dos dados permitiram verificar o comportamento dos indicadores e os resultados dos programas implementados. Os dados evidenciaram que, apesar dos programas, as perdas de água se mantiveram elevadas, e as ações de eficiência energética foram mais eficazes. Os programas implementados foram pontuais, voltados prioritariamente para ações técnicooperacionais, carecendo de um planejamento mais estratégico por parte da empresa. Do estudo, concluiu-se que o sucesso das ações para o uso eficiente da água e energia, obrigatoriamente, exige a superação das abordagens parciais e voltadas para a dimensão técnico-operacional, devendo-se incorporar a noção da complexidade e o caráter intersetorial e integrado.
\end{abstract}

Palavras-chave: perdas de água; eficiência energética; abastecimento de água.

\begin{abstract}
In Brazil, water supply systems still present water losses and low energy efficiency. The study aimed to analyze the factors that have influenced the effectiveness of the management of water losses and energy supply systems operated by Empresa Baiana de Águas e Saneamento (Embasa) in metropolitan region of Salvador (RMS). The research and the evaluation of the data allowed us to verify the behavior of the indicators and the results of the implemented programs. The data showed that, despite the programs, water losses remained high, and the energy efficiency actions were more effective. The implemented programs were timely, targeted primarily for technical and operational actions, lacking a more strategic planning for the company. The study concluded that the success of the actions for the efficient use of water and energy necessarily requires the overcoming of partial and focused approaches to technical and operational dimension and to incorporate the notion of complexity, intersectoral and integrated character
\end{abstract}

Keywords: water loss; energy efficiency; water supply.

\section{INTRODUÇÃO}

A água, elemento essencial à vida e às atividades humanas, tornou-se ao longo da última década um dos principais temas de discussão. Se por um lado o acesso à água potável ainda não é universal, por outro os níveis de desperdício e poluição são crescentes. Atualmente, no mundo, cerca de um bilhão de pessoas têm dificuldade de acesso à água potável, e os mananciais vêm sendo alvo de intensa exploração e degradação (UN-HABITAT, 2011). Foi diante da importância da água para os povos do mundo que a Organização das Nações Unidas (ONU) definiu o acesso à água potável como um direito humano essencial.
A crescente demanda por água para os diversos usos e a intensificação da degradação ambiental fizeram emergir no Brasil uma série de ações para a adoção de tecnologias e práticas de uso racional da água e controle de perdas em sistemas de abastecimento.

Também, os sistemas de abastecimento de água têm demandado consumo crescente de energia, ampliando os custos de operação. No que se refere à eficiência energética, às atividades de captação, tratamento e distribuição de água, bem como às inerentes ao esgotamento sanitário têm a energia elétrica como principal insumo. Nos sistemas de abastecimento de água e esgotamento sanitário, a energia elétrica 
é empregada na operação do sistema, na iluminação das áreas administrativas e nos serviços auxiliares.

Dessa forma, o gerenciamento integrado das perdas totais (reais e aparentes) de água e a eficiência energética nos sistemas são hoje um imperativo, devendo esse esforço ser adicionado ao escopo dos projetos, por razões de caráter ambiental, social e econômico.

Apesar das experiências para o controle das perdas de água e eficiência energética, os prestadores de serviços de abastecimento de água e de esgotamento sanitário no Brasil, o que inclui a Empresa Baiana de Águas e Saneamento (Embasa), ainda demonstram níveis elevados de perdas em relação aos padrões internacionais de países desenvolvidos, onde esse indicador atinge patamares da ordem de $10 \%$, como Japão e Alemanha, por exemplo (ITONAGA, 2005).

Sendo assim, com base na realidade descrita, tem-se a necessidade premente de estudar de forma conjunta a gestão das perdas de água e a gestão do uso eficiente de energia elétrica. Logo, o presente trabalho objetivou averiguar essa problemática com vistas a identificar os fatores técnicos, operacionais, econômico-financeiros, administrativos e gerenciais que têm influenciado na efetividade da gestão das perdas de água e eficiência energética em sistemas públicos de abastecimento de água da Embasa.

\section{PERDAS DE ÁGUA E EFICIÊNCIA ENERGÉTICA EM SISTEMAS PÚBLICOS DE ABASTECIMENTO}

\section{Perdas de água}

A perda de água é considerada como um dos principais indicadores de desempenho operacional dos prestadores de serviço público de abastecimento de água em todo o mundo. As perdas ocorrem em todos os componentes de um sistema de abastecimento de água, desde a captação até a distribuição, entretanto a magnitude dessas perdas depende de cada unidade (BRASIL, 2008).

A universalização do acesso à água em condições de potabilidade, com implantação e manutenção de uma infraestrutura capaz de atender de maneira adequada e otimizada à demanda dos grandes centros urbanos, é o grande desafio dos prestadores de serviço público de abastecimento de água para as próximas décadas. Destarte, o controle das perdas nos sistemas de abastecimento de água, somado a projetos apropriados e ao uso racional da água pela população, é um instrumento fundamental para a sustentabilidade dos recursos hídricos.

Sob a visão econômica, as perdas de água nos sistemas de abastecimento público geram desperdício dos recursos públicos, o que normalmente é repassado para o usuário. A redução dos gastos referentes às perdas propiciaria maior aproveitamento do sistema existente, direcionando a aplicação dos recursos economizados para melhorias necessárias.
Nesse contexto, é importante ressaltar que o controle das perdas de água em sistemas de abastecimento público se torna uma necessidade, pois os volumes não contabilizados não são faturados. A quantificação das perdas é de suma relevância para os prestadores de serviço no que diz respeito à eficiência de distribuição de água, além de aspectos econômicos e ambientais.

Desde a captação, passando pela distribuição, até o consumidor final ocorrem perdas de água de vários tipos que em grande parte são causadas pela operação e manutenção deficientes das tubulações e pela inadequada gestão comercial dos prestadores de serviço público de abastecimento de água. Analisando o Sistema Nacional de Informações sobre Saneamento (SNIS, 2011), observa-se que um dos principais problemas enfrentados pelos prestadores de serviços públicos no Brasil são as questões das elevadas perdas. De acordo com o SNIS (2011), na amostra de sistemas pesquisados, perde-se $43 \%$ do volume da água distribuído em relação à água captada, sendo então fundamental estabelecer estratégias de controle das perdas de água, principalmente em regiões em que existem escassez e conflitos pelo seu uso. No estado da Bahia e nos municípios atendidos pela Embasa, por exemplo, o volume de água não contabilizada assumiu o percentual de $38 \%$ no ano de 2009 (SNIS, 2011).

Miranda (2002) apresenta como principais fatores para o elevado índice de perdas de água nos prestadores de serviço público de abastecimento de água:

- baixa capacidade institucional e de gerenciamento dos sistemas;

- pouca disponibilidade de recursos para investimentos em ações de desenvolvimento tecnológico na rede de distribuição e na operação dos sistemas;

- cultura do aumento da oferta e do consumo individual, sem preocupações com a conservação e o uso racional;

- decisões de ampliação da carga hidráulica e extensão das redes até áreas mais distantes dos sistemas, para atendimento aos novos consumidores, sem os devidos estudos de engenharia.

Para Baggio (2000), o controle de perdas envolve implantar um modelo de gerenciamento da rotina do trabalho no processo de operação de sistemas de abastecimento de água, democratizar as informações e sensibilização para a criação de consciência sobre as questões de perdas de água, promover ações para a conscientização do problema e bloquear as causas predominantes das perdas de água.

Cheung et al. (2009) propõem a elaboração de uma estratégia para controle de perdas nomeada check-list e baseada nas seguintes perguntas: quanta água está sendo perdida? Onde a água está sendo perdida? Por que a água está sendo perdida? Como melhorar o desempenho do sistema? Como sustentar o desempenho do sistema?

Tsutiya (2004) sugere incorporar o ciclo do Plan, Do, Check, Act (PDCA) nos processos envolvidos no controle de perdas, método este 
que é bastante semelhante ao indicado por Baggio (2000). Para Tsutiya (2004), devem ser definidas metas globais e setoriais para os dois tipos de perdas (reais e aparentes) e estabelecidos indicadores de controle para cada ação desenvolvida.

Qualquer que seja a proposta utilizada para o diagnóstico de perdas de água, é necessária a realização das atividades de controle de perdas reais e aparentes por meio de um planejamento integrado em toda a instituição ou empresa responsável pelo abastecimento de água.

\section{Eficiência energética}

Dados da Alliance to Save Energy (ASE, 2002) revelam que entre 2 e $3 \%$ do consumo de energia mundial é usado no bombeamento e tratamento de água para residências e indústrias. No Brasil, esses sistemas consomem aproximadamente 7,8 bilhões de kWh por ano, segundo informações de 2009 do SNIS. Esse montante representa um gasto anual com energia elétrica da ordem de R\$ 2 bilhões (SNIS, 2011). Considerando o consumo total de $2 \%$ de energia elétrica no Brasil, esse valor equivale a 8,3 bilhões de $\mathrm{kWh} /$ ano, que são utilizados por prestadores de serviços públicos de abastecimento de água em todo o país.

As despesas totais dos prestadores de serviços públicos de abastecimento de água e esgotamento sanitário com energia elétrica no Brasil chegam a R\$ 1,5 bilhão por ano, variando entre 6,5 e 23,8\%, com média de $12,2 \%$, para os sistemas de abastecimento de água e de esgotamento sanitário operados por companhias estaduais (ELETROBRAS, 2005).

Estima-se que a ineficiência energética na área de saneamento básico seja de 25 a 30\% (GOMES et al., 2009). Essa despesa gerada pelo desperdício normalmente é repassada ao consumidor na tarifa.

Para Tsutiya (2001), o consumo de energia tem relação direta com as perdas de água, pois é necessário cerca de 0,6 a $0,7 \mathrm{kWh}$ para produzir $1 \mathrm{~m}^{3}$ de água potável. Dessa forma, fica estabelecida uma relação direta entre a necessidade da eficiência hidráulica e energética para o bom gerenciamento dos sistemas de abastecimento de água (CHEUNG et al., 2009).

A Embasa tem gasto anual de aproximadamente 123 milhões de reais com o insumo energia elétrica para uso nos seus mais diversos sistemas. Hoje em dia, esse insumo representa o segundo maior custo da empresa - o primeiro são os custos com folha de pagamento de pessoal (EMBASA, 2011). Além do constante aumento dos custos com energia elétrica ao longo dos anos, seja pela elevação de tarifas, seja pelo crescimento dos sistemas existentes ou pela incorporação de novos sistemas, observa-se um alto percentual nas perdas totais de água na distribuição, índices que em alguns municípios e na capital do estado alcançam patamares acima de 40\% (SNIS, 2011).

Em geral, o consumo de energia elétrica nos sistemas de abastecimento de água e esgotamento sanitário é assim distribuído (ORMSBEE;
WALKI, 1989): motores ficam com 90\%; serviços auxiliares com 7,5\%; e iluminação com 2,5\%.

Para a American Water Works Association Research Foundation (AWWA, 1999), os custos com energia elétrica representam 34\% dos custos totais dos prestadores de serviços de abastecimento de água e esgotamento sanitário nos Estados Unidos. Esse valor significa que os gastos com energia elétrica são apenas superados pelos pagamentos da folha de pessoal, que representam $35 \%$ dos gastos totais das empresas.

Para Marques, Haddad e Guardia (2007, p. 2), a gestão energética deve abordar as seguintes medidas:

- conhecimento das informações concernentes a fluxos de energia, das ações que influenciam esses fluxos e, ainda, dos processos e atividades que usam a energia e a relacionam com um produto ou serviço;

- acompanhamento dos índices de controle, como consumos de energia, custos específicos, fator de utilização etc.;

- atuação nos índices que visam reduzir o consumo energético por meio da implementação de ações que buscam a utilização racional da energia.

De acordo com a Rede de Capacitação e Extensão Tecnológica de Saneamento (ReCESA) (BRASIL, 2008, p. 43), as principais questões que devem ser analisadas visando à redução das despesas com energia elétrica são: tarifação imprópria e falhas administrativas, falhas de ajustes de equipamentos, superdimensionamento da potência dos equipamentos e falta ou falhas de controle operacional.

A fim de utilizar energia elétrica de forma mais eficiente, existem métodos que podem ser aplicados na fase de concepção de um sistema de abastecimento de água, bem como na operação. Ionescu (2004, p. 5) sistematiza os principais meios para reduzir o consumo de energia elétrica, conforme apresentado no Quadro 1.

A ASE (2007) elenca algumas medidas que, uma vez implementadas, melhoram significativamente a eficiência energética nos sistemas de abastecimento de água e de esgotamento sanitário. Tais medidas e alguns períodos de retorno médios para cada um dos investimentos realizados estão apresentados no Quadro 2.

Tsutiya (2001) traz um fluxograma com as ações iniciais para a redução do custo com energia elétrica em sistemas de abastecimento de água (Figura 1).

Segundo Marques, Haddad e Guardia (2007), não basta a implementação de ações, sejam elas administrativas, sejam operacionais, como proposto por Tsutiya (2001); tornam-se necessários a definição de metas e responsáveis e efetivos acompanhamentos de acordo com um programa de gestão energética. Tal afirmação evidencia a necessidade de considerar os diversos fatores que influenciam a gestão de perdas e energia quando da concepção de programas de controle. 


\section{METODOLOGIA}

Para o desenvolvimento da pesquisa foram realizados os seguintes estudos:

- pesquisa documental sobre os programas e projetos de perdas de água e eficiência energética desenvolvidos pela Embasa na região metropolitana de Salvador (RMS);

- estudo de base de dados secundários sobre o comportamento das perdas de água e energia em unidades operacionais da RMS, a saber: Sistema Integrado de Abastecimento de Água (SIAA) de Salvador, de Simões Filho e de Lauro de Freitas. Este estudo foi feito fundamentado em informações dos sistemas de informação da Embasa e do SNIS.

\section{Pesquisa documental}

A pesquisa documental compreende o levantamento e as análises de documentos de seu interesse. Nesta investigação foram estudados os principais programas de gestão de perdas de água e eficiência energética já realizados na RMS pela Embasa, em um horizonte de 15 anos. Os documentos e relatórios foram examinados com base nas categorias analíticas delimitadas para o estudo, a saber: aspectos técnicos, operacionais, administrativos e gerenciais. Posteriormente, foi construído um quadro síntese para cada programa identificando as categorias e variáveis contempladas em suas ações à luz do referencial teórico selecionado.

Quadro 1 - Meios para reduzir as perdas de energia elétrica.

\begin{tabular}{|c|c|}
\hline Dimensão & \\
\hline \multirow{8}{*}{ Técnica } & $\begin{array}{l}\text { Escolher o número de unidades instaladas de tal } \\
\text { forma a evitar uma relação estreita entre elas e a } \\
\text { potência elétrica total absorvida pelo sistema de } \\
\text { abastecimento de água. }\end{array}$ \\
\hline & Escolher a tensão elétrica adequada para o sistema. \\
\hline & $\begin{array}{l}\text { Utilizar a velocidade de rotação variável nos } \\
\text { mecanismos de bombeamento, nos sistemas de } \\
\text { abastecimento de água que não têm reservação. }\end{array}$ \\
\hline & $\begin{array}{l}\text { Realizar o fornecimento de energia elétrica e } \\
\text { distribuição de instalações (incluindo subestações), } \\
\text { nos centros de carga dos consumidores de energia. }\end{array}$ \\
\hline & $\begin{array}{c}\text { Utilizar sistemas locais de bancos capacitores para } \\
\text { compensação de energia reativa (melhorando o fator } \\
\text { de potência). }\end{array}$ \\
\hline & $\begin{array}{l}\text { Estabelecer medidas tecnológicas no sistema de } \\
\text { abastecimento de água para reduzir, ou mesmo } \\
\text { eliminar, o consumo de energia elétrica em } \\
\text { momentos de pico de carga no sistema elétrico, } \\
\text { quando os parâmetros de qualidade da energia } \\
\text { elétrica fornecida são baixos. }\end{array}$ \\
\hline & $\begin{array}{l}\text { Automatizar parcial ou totalmente os processos } \\
\text { tecnológicos do abastecimento de água. }\end{array}$ \\
\hline & $\begin{array}{l}\text { Eliminar perdas no sistema de abastecimento de } \\
\text { água, incluindo instalações de consumo. }\end{array}$ \\
\hline Administrativa & $\begin{array}{c}\text { Proporcionar a formação adequada para o } \\
\text { pessoal que manuseia a exploração do sistema de } \\
\text { abastecimento de água. }\end{array}$ \\
\hline
\end{tabular}

Fonte: lonescu, 2004.
Também foram averiguados aspectos relativos à política da empresa no que diz respeito ao controle das perdas de água e à busca da melhoria na eficiência energética, fundamentado em informações provenientes do Planejamento Estratégico 2012-2015, documentos internos, relatórios finais de atividades, atas das resoluções da então diretoria de operações e da presidência da Embasa, além de outros documentos concernentes ao assunto disponíveis nas diretorias e superintendências da empresa.

\section{Estudo de base de dados secundários}

Foram realizadas coleta e análises de dados secundários, considerando três situações, sendo elas:

- perdas de água no SIAA de Salvador, de Simões Filho e de Lauro de Freitas, com base nos dados do sistema de informações do Controle Operacional de Água e Esgoto (Copae), que que é um sistema utilizado pela Embasa para o acompanhamento da operação dos processos de produção e distribuição de água e esgotamento sanitário, entre 2000 e 2011, visando verificar se os diversos

Quadro 2 - Medidas para melhorar a eficiência energética no abastecimento de água com períodos de amortização ilustrativos.

\begin{tabular}{|c|c|c|}
\hline Área & Função & $\begin{array}{l}\text { Período padrão } \\
\text { de amortização } \\
\text { (anos) }\end{array}$ \\
\hline $\begin{array}{l}\text { Tarifas de } \\
\text { energia }\end{array}$ & $\begin{array}{l}\text { Redução da demanda } \\
\text { durante os períodos de pico } \\
\text { das tarifas de energia }\end{array}$ & $\begin{array}{c}\text { O-2 } \\
\text { (dependendo da } \\
\text { capacidade de } \\
\text { armazenamento) }\end{array}$ \\
\hline \multirow{2}{*}{$\begin{array}{l}\text { Instalações } \\
\text { elétricas }\end{array}$} & $\begin{array}{c}\text { Otimização de energia com } \\
\text { capacitores }\end{array}$ & $0,8-1,5$ \\
\hline & $\begin{array}{c}\text { Redução no desequilíbrio da } \\
\text { voltagem }\end{array}$ & $1-1,5$ \\
\hline \multirow{2}{*}{$\begin{array}{l}\text { Operação e } \\
\text { manutenção }\end{array}$} & $\begin{array}{c}\text { Manutenção de rotina nas } \\
\text { bombas }\end{array}$ & 2 \\
\hline & $\begin{array}{l}\text { Manutenção e reabilitação do } \\
\text { poço profundo }\end{array}$ & $1-2$ \\
\hline \multirow{5}{*}{$\begin{array}{l}\text { Produção e } \\
\text { distribuição }\end{array}$} & $\begin{array}{c}\text { Automação (como telemetria, } \\
\text { Supervisory Control and Data } \\
\text { Acquisition e controle eletrônico } \\
\text { na modulação das válvulas), por } \\
\text { exemplo, para controlar pressão e } \\
\text { vazão nas redes e para otimizar a } \\
\text { operação das bombas. }\end{array}$ & $0-5$ \\
\hline & Nova bomba eficiente & $1-2$ \\
\hline & Novo motor eficiente & $2-3$ \\
\hline & Substituição da turbina & 0,5 \\
\hline & $\begin{array}{l}\text { Otimização da rede de } \\
\text { distribuição (removendo válvulas } \\
\text { desnecessárias, setorizando e } \\
\text { instalando drivers de variação da } \\
\text { velocidade e válvulas reguladoras. }\end{array}$ & $0,5-3$ \\
\hline \multirow[t]{2}{*}{ Uso final } & $\begin{array}{l}\text { Programa de incentivo para uso } \\
\text { de tecnologias eficientes }\end{array}$ & $2-3$ \\
\hline & Efetiva medição de consumo & $1-2$ \\
\hline
\end{tabular}

Fonte: ASE, 2007. 
programas realizados pela Embasa repercutiram positiva ou negativamente nos resultados institucionais. Os indicadores Água Não Contabilizada (ANC), Água Não Faturada (ANF) e Índice de Perdas por Ligação (IPL) foram comparados com os divulgados no SNIS e os apresentados nas referências bibliográficas estudadas;

- quatro programas de controle de perdas, sendo três para perdas físicas e um para perdas aparentes, além de 12 contratos de manutenção que incluíam ações comerciais como cobrança, corte, recorte, religação e pequenas intervenções operacionais, a exemplo da retirada de vazamentos em redes distribuidoras e ramais prediais. Buscou-se identificar os fatores que influenciaram os resultados atingidos e, ainda, os marcos conceituais e metodológicos da concepção dos programas. Por fim, foi constatada a adesão dos programas às categorias analíticas do presente estudo (aspectos técnicos, operacionais, administrativos e gerenciais), como estratégia de avaliar a amplitude e o caráter das ações dos programas;

- dois projetos de eficiência energética. Um deles é o convênio de eficiência energética com a companhia Centrais Elétricas Brasileiras (Eletrobras), que teve como objeto a Estação Elevatória Teodoro Sampaio/R1 Duna (ECV-017/2004), e o projeto que estava sendo implantado na unidade operacional do Parque da Federação. Os dois projetos estavam vinculados à Embasa/RMS e ao SIAA de Salvador, de Simões Filho e de Lauro de Freitas. Foram analisados o comportamento do indicador de consumo específico $\left(\mathrm{kWh} / \mathrm{m}^{3}\right)$ e o consumo específico normalizado $\left(\mathrm{kWh} / \mathrm{m}^{3} \mathrm{x} 100 / \mathrm{H}\right)$, ambos comparados com as informações disponibilizadas pelo SNIS e com as referências bibliográficas elencadas.

\section{Análise dos dados}

A análise documental dos programas de controle de perdas de água e eficiência energética já implementados pela Embasa na RMS permitiu entender as ações planejadas ao longo do tempo e seus reflexos na gestão das perdas. Objetivou-se caracterizar os programas, identificar os fatores que influenciaram os resultados atingidos e, ainda, estudar seus marcos conceituais e metodológicos.

A avaliação dos dados secundários oportunizou verificar o comportamento dos indicadores relacionados às perdas de água do SIAA de Salvador, de Simões Filho e de Lauro de Freitas que foram extraídos do sistema de informação da Embasa/Copae. Propôs-se constatar se os programas e projetos produziram resultados para o controle das perdas de água no sistema investigado. Os indicadores foram comparados com os apresentados nacionalmente pelo SNIS e os disponíveis na literatura, possibilitando assim a análise dos resultados dos programas.

Quanto aos indicadores de eficiência energética, foi avaliado o programa de eficientização energética da Estação Elevatória Teodoro Sampaio/R1 Duna, com foco no indicador relacionado à capacidade específica $\left(\mathrm{kWh} / \mathrm{m}^{3}\right)$ antes e depois da sua implementação.

\section{RESULTADOS}

\section{Análise dos indicadores de perdas de água da Embasa}

Em relação às perdas de água foram realizadas análises dos indicadores ANC, ANF e IPL da Embasa em 2000 e 2011 extraídos do sistema

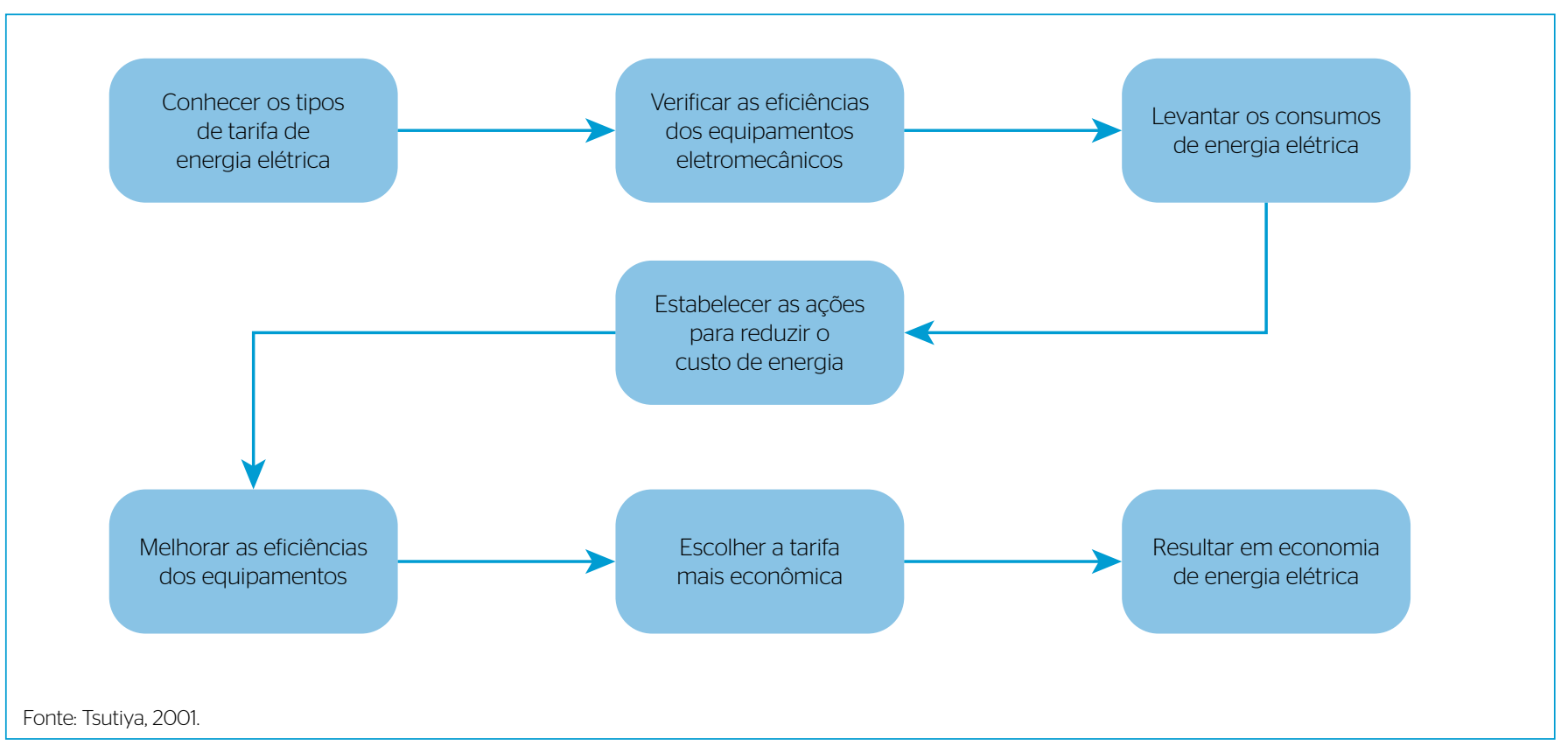

Figura 1 - Ações iniciais para redução dos custos de energia elétrica em sistemas de abastecimento de água. 
de informações do Copae. Dos resultados, pôde-se perceber que a empresa vem apresentando altos índices de perdas, embora no período estudado tenha ocorrido decréscimo dos indicadores ANC, ANF e IPL (Figura 2). Além de o desempenho ter sido afetado pelo baixo investimento em ações de controle de perdas, o modelo de atuação da Embasa, pautado em programas com ações pontuais em áreas-piloto, teve papel importante.

Analisando a Figura 2, observa-se o comportamento decrescente dos três indicadores ao longo da série analisada (2000-2011). Quanto ao indicador ANF houve redução de 9,8\% (39,2\% em 2000 para 29,4\% em 2011) no período em foco. Essa diferença é justificada por Marcka (2004), para quem o ANF é bastante influenciado pelo consumo menor que o mínimo $\left(10 \mathrm{~m}^{3}\right)$. De fato, no período averiguado, o percentual de micromedição evoluiu de 87,3 para $94,8 \%$, tendo-se o número de ligações consumindo menos que $10 \mathrm{~m}^{3} / \mathrm{mês}$, valor esse ainda maior em razão da inibição no consumo provocado pelo hidrômetro (EMBASA, 2012). Já para o indicador ANC, o decréscimo foi de apenas $2,4 \%$, pelo fato de que no ano 2000 existia ANC de $39,2 \%$ para um número de ligações ativas de 1,5 milhões, enquanto em 2011 o indicador era de 36,8\% para 2,5 milhões de ligações ativas faturadas. Para o indicador IPL, a redução foi em torno de $32 \%$ ao longo de todo o período (397 L/dia × ligações em 2000 para $271 \mathrm{~L} /$ dia $\times$ ligações em 2011).

Os resultados corroboram com as considerações de Werdine (2002) e Miranda (2002), para os quais o indicador em percentual não é representativo para uma análise. O indicador ANC teve pequena redução, enquanto o IPL, que é um indicador de desempenho, diminuiu em $32 \%$ no período analisado, o que mostra um resultado significativo se analisada a perda/ligação.

\section{Análise dos indicadores de perdas de água da Embasa: região metropolitana de Salvador}

As maiores perdas de água em volume da Embasa ocorreram na área de influência da diretoria metropolitana e, mais precisamente, no SIAA de Salvador, de Simões Filho e de Lauro de Freitas, operado pelas unidades regionais de Salvador. O volume consumido no SIAA de Salvador, de Simões Filho e de Lauro de Freitas foi mais do que a metade (51\%) da água distribuída pela empresa. Salienta-se que o SIAA de Salvador, de Simões Filho e de Lauro de Freitas representa cerca de 73\% da ANF e $60 \%$ da ANC, se comparado ao estado da Bahia. Além disso, o indicador IPL foi cerca de 2,6 vezes o IPL médio estadual. Esse sistema é o maior do estado em termos de volume de água produzido, de número de ligações e também de perdas de água.

Na Figura 3, pôde-se observar o comportamento dos indicadores ANF, ANC e IPL durante o período estudado (2000-2011). No que se refere aos indicadores ANC e ANF, os valores estavam em patamares elevados, verificando-se uma flutuação durante o período analisado. Do ponto de vista global, visualizou-se que ao longo da série examinada os resultados foram muito discretos, até mesmo levando em conta os investimentos realizados e o fato de o sistema em foco ser o mais importante do prestador do serviço, envolvendo até mesmo a capital do estado. Considerando apenas o indicador ANF, a redução

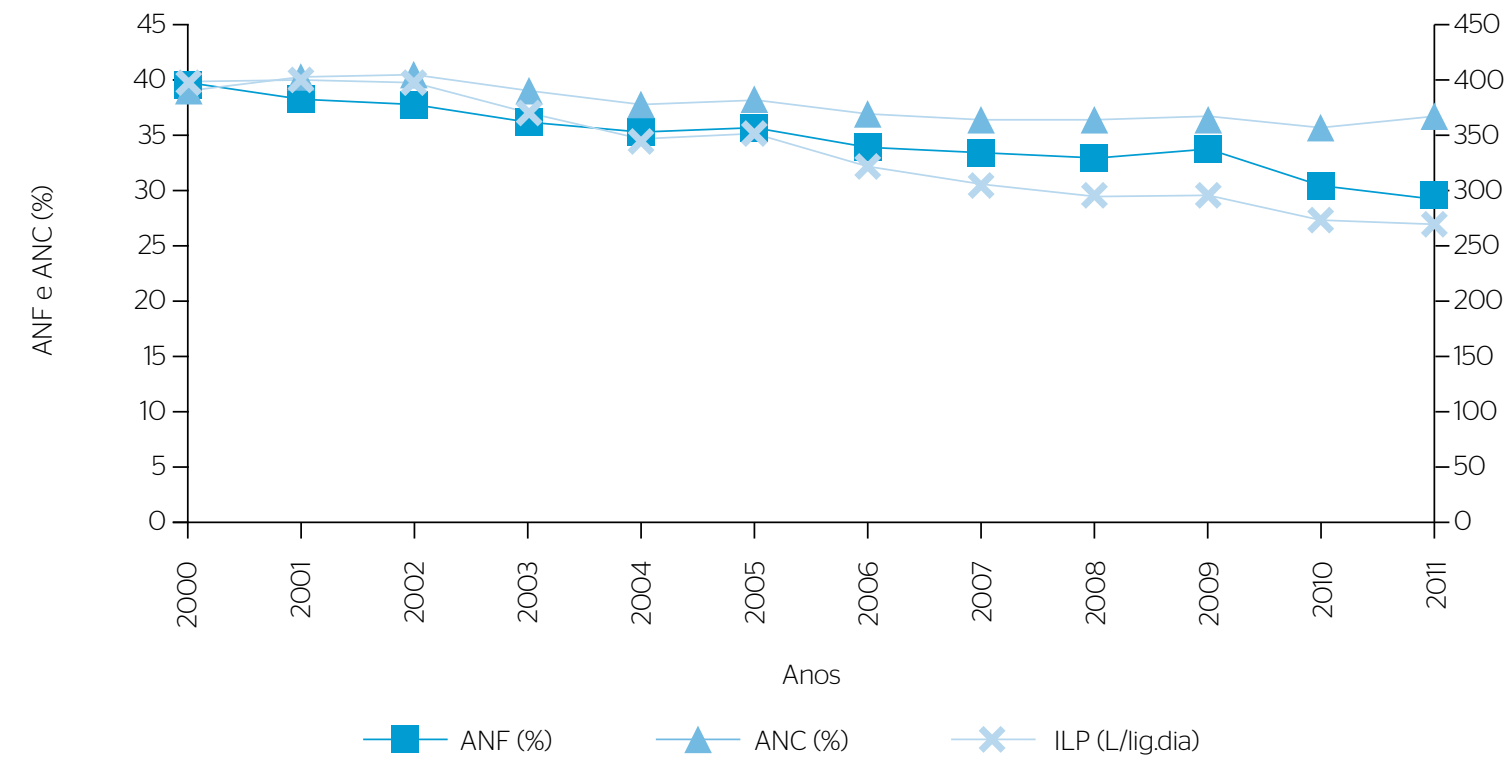

Fonte: Embasa, 2012

ANC: Água Não Contabilizada; ANF: Água Não Faturada; IPL: Índice de Perdas por Ligação.

Figura 2 - Evolução dos indicadores Água Não Faturada, Água Não Contabilizada e Índice de Perdas por ligação na Embasa. 
foi de apenas 2,4\%. Nos anos de 2001 e 2002, constatou-se que o indicador ANF alcançou os maiores valores, 50,8 e 51\%, respectivamente, atingindo, em 2005, 49,7\%, porcentagem ainda muito elevada. Nesse período, viu-se que a micromedição evoluiu de 80,20\% (2000) para 89,47\% (2011) (EMBASA, 2012), uma evolução baixa para um período de uma década e diante dos investimentos já realizados em micromedição nesse sistema.

Analisando a Figura 3, é evidente que o indicador ANC se comportou de forma semelhante ao ANF, o que já era esperado, visto tratar-se de sistema com ações desenvolvidas pela mesma superintendência. O comportamento dos indicadores de perdas, ANC e ANF da Embasa é influenciado pelas práticas de gestão de cada diretoria e pelos programas implantados em cada sistema. Com isso, os resultados podem divergir. Também, nesse caso, a instalação de novos hidrômetros influenciou nos resultados.

A redução de apenas 1,2\% para o indicador ANC em todo o período estudado é um resultado bastante preocupante, tendo em vista o volume de água não contabilizado durante todo o tempo.

O indicador IPL apresentou resultado positivo (redução de 27\%) no decorrer do período estudado, principalmente por conta do acréscimo de novas ligações. No intervalo analisado foram acrescidas cerca de 190 mil novas ligações, notadamente nas unidades regionais da Bolandeira (UMB) e Pirajá (UMJ), representando acréscimo de 51\% de novas ligações no período enfocado (EMBASA, 2012). É importante ressaltar que o indicador sofreu redução em função, basicamente, do aumento do número de novas ligações implantadas/recuperadas no período. Ou seja, não se pode atribuir a redução desse indicador apenas às ações de controle de perdas.

De acordo com a Embasa (2012), no período de 2010 e 2011 para o sistema analisado: o volume distribuído aumentou $12,5 \%$, e o volume de ANC, 9,6\%, enquanto o número de ligações teve acréscimo de $51 \%$. Sendo assim, pôde-se inferir que ou a Embasa está distribuindo melhor a água para um número de ligações significativamente maior, havendo a redução do IPL, ou ocorreram intermitências no abastecimento em determinadas áreas.

\section{Resultados dos programas de perdas de água no SIAA de Salvador, de Simões Filho e de Lauro de Freitas}

Até o ano de 1998, a Embasa não tinha conhecimento da problemática de perdas de água da cidade de Salvador. No início de 1999, as perdas começaram a ser calculadas na Superintendência Metropolitana de Salvador, ainda com algumas indefinições, principalmente no que dizia respeito à setorização, que só foi concluída em dezembro de 1999 (EMBASA, 1999).

Em 1993, o indicador ANC para o SIAA de Salvador era de 56\% e em 1999 chegou a 49,9\%, havendo pequena queda no período, sobretudo pela adequação entre a "oferta $\times$ demanda" (MAGALHÃES, 2001).

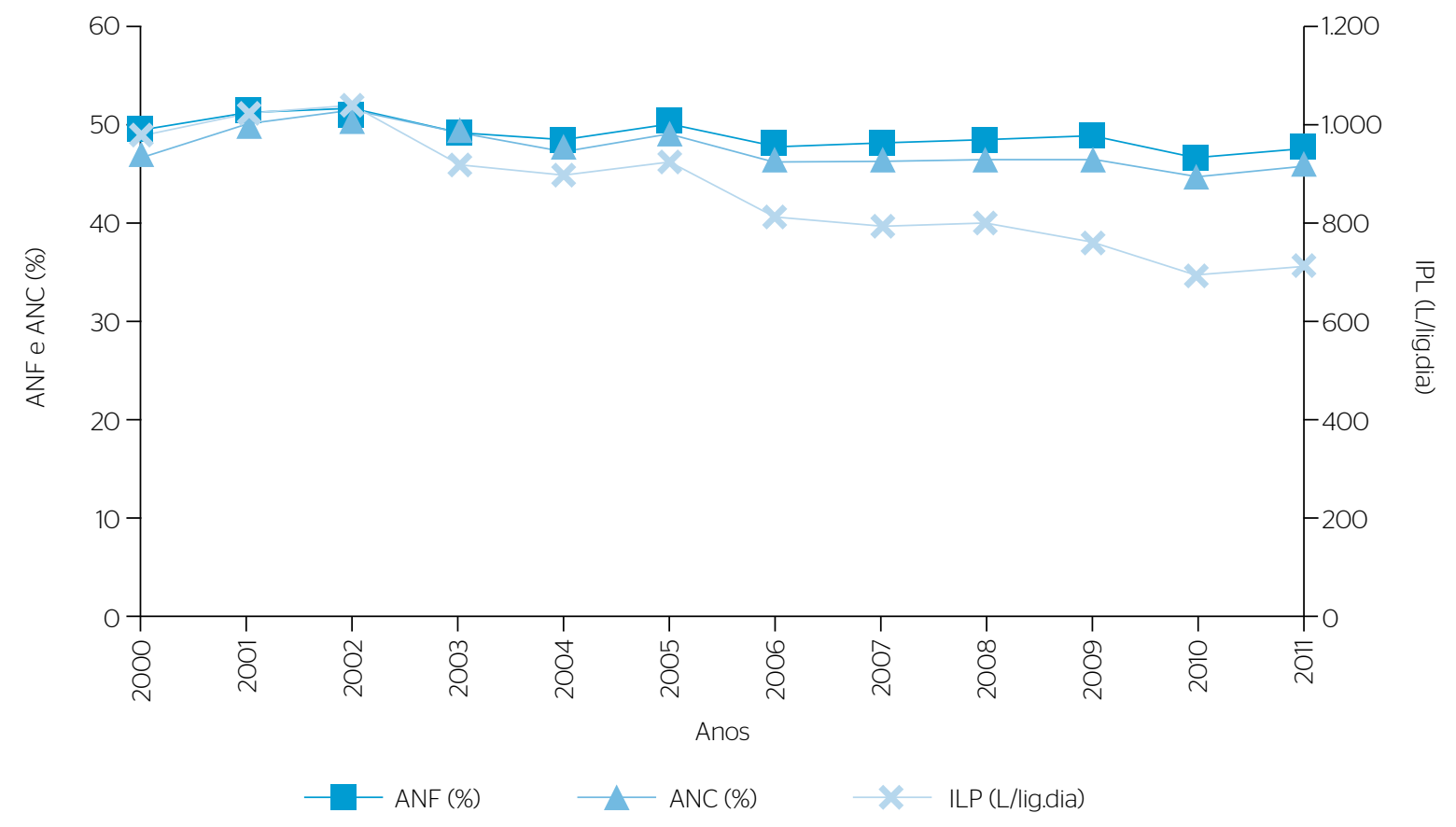

Fonte: Embasa, 2012

ANC: Água Não Contabilizada; ANF: Água Não Faturada; IPL: Índice de Perdas por Ligação.

Figura 3 - Evolução dos indicadores Água Não Faturada, Água Não Contabilizada e Índice de Perdas por Ligação no Sistema Integrado de Abastecimento de Água de Salvador, de Simões Filho e de Lauro de Freitas. 
Considerando as informações disponíveis, foi possível verificar o comportamento das perdas de água em relação aos programas de perdas de água realizados no período de 1992 a 2012 (Figura 4). Como um programa não apresenta resultados de forma imediata, estes foram plotados graficamente, mais ou menos um ano após a conclusão dos trabalhos de campo.

Analisando a Figura 4, conclui-se que os dois primeiros programas (Contrato 1, de n ${ }^{\circ}$ 254/1996, e Contrato 2, de n ${ }^{\circ} 231 / 2003$ ) se encontram em pontos em que as perdas eram decrescentes. $\mathrm{O}$ último programa (Contrato 3, de n. ${ }^{\circ}$ 672/2008) passou a auferir resultados a partir de 2010, sendo eles registrados efetivamente em 2011.

Com a efetivação do Contrato 1, o indicador ANC atingiu um dos valores mais baixos, embora em patamar elevado, ao longo do período estudado (47\% no ano 2000). Ou seja, logo após a implantação do programa, houve queda de aproximadamente 3\%. Esse fato coincide com o início da setorização, que aconteceu em dezembro de 1999. A partir do ano 2000, o indicador ANC passou a subir mais uma vez, atingindo patamares em torno de $50 \%$, voltando a reduzir apenas por volta do fim de 2005, após a implementação definitiva do Contrato 2. Pôde-se perceber que de 2005 a 2007 houve inflexão na curva apresentada, após implantação da setorização, ocasião em que foram reduzidos 2,7\% do indicador ANC e $132 \mathrm{~L} /$ ligações ao dia do indicador IPL, números ainda muito baixos. Esse período coincide com a conclusão do Contrato 2, quando se deu a divulgação dos resultados obtidos, treinamentos de pessoal e uma forte disseminação da questão das perdas, estimulando a implantação de válvulas redutoras de pressão em toda a Embasa/RMS. Mesmo com essas ações, as perdas mantiveram-se altas. No período de 2007 a 2009 os indicadores ficaram estáveis e em patamares elevados, voltando a reduzir em meados de 2009 e 2010, quando já se iniciava a implantação das válvulas como atividade do Contrato 3 , as quais não foram suficientes para gerar impactos significativos (ANDRADE SOBRINHO, 2012).

De forma geral, não foi possível inferir que os programas tenham contribuído para a redução, mesmo que limitada, dos indicadores, visto que os resultados foram melhores nas zonas de abastecimento alvo dos programas, porém de pouco significado para o sistema como um todo.

É importante salientar que um dos resultados indiretos dos programas se relaciona ao estímulo à construção de uma cultura de controle de perdas, seja ela pelo aprendizado com a empresa contratada, seja motivada por metas mais desafiadoras propostas pela alta direção conhecedora da implementação do programa nas unidades regionais.

Constatou-se que, durante o período dos contratos, ocorreu pequena redução dos indicadores, passando por um período de estabilização ou leve acréscimo, até o início de um novo programa específico.

Os resultados sugeriram que o controle de perdas de água via programas, com prazo de duração predeterminado e área de abrangência

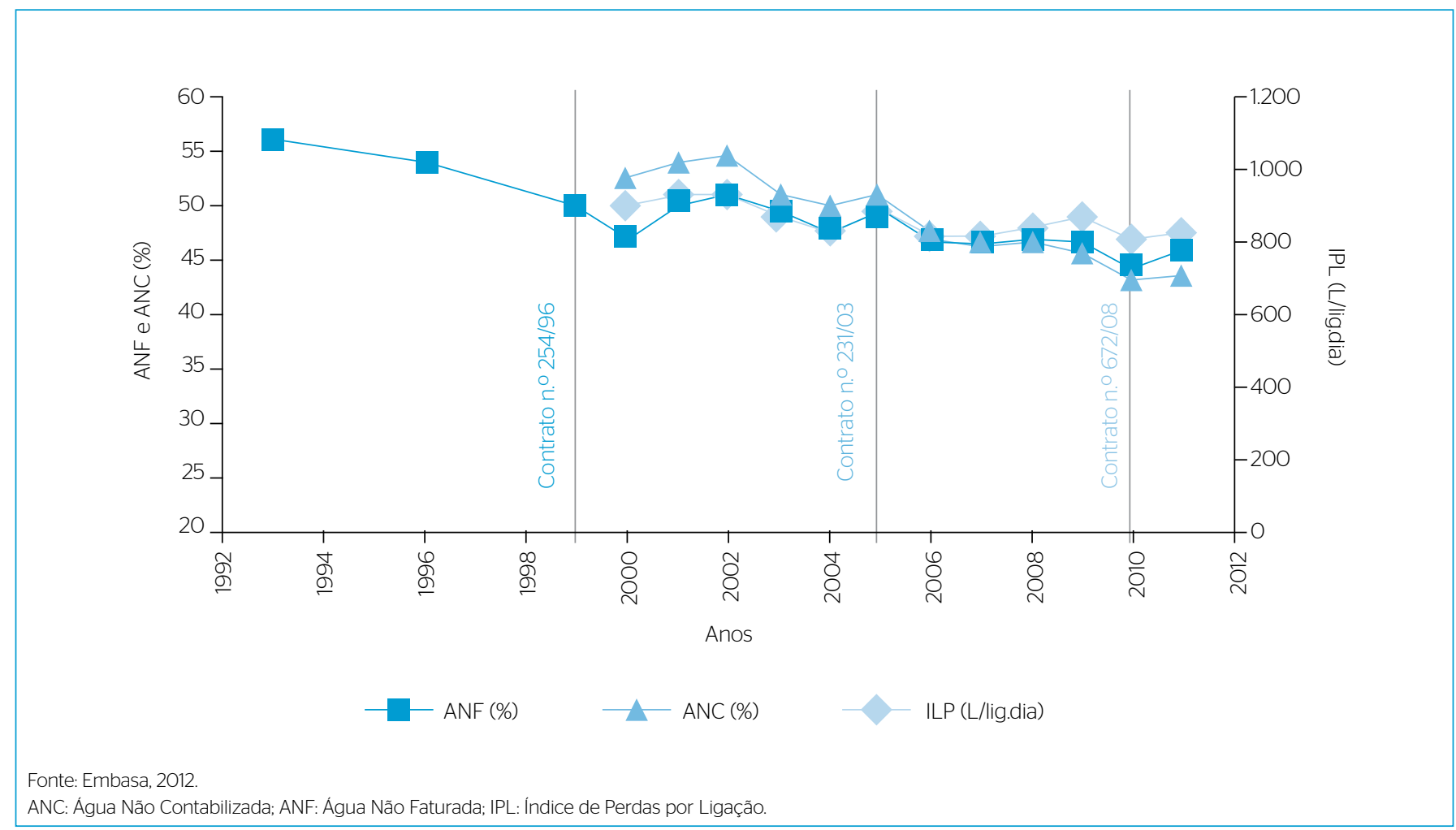

Figura 4 - Comportamento das perdas de água no Sistema Integrado de Abastecimento de Água de Salvador, de Simões Filho e de Lauro de Freitas. 
limitada, constitui uma estratégia de pouca efetividade. Os resultados mostram que é necessário empreender estratégias mais amplas e continuadas, sustentadas em forte planejamento e no engajamento não só do corpo técnico-gerencial, mas principalmente da alta direção, que deve garantir recursos perenes para o desenvolvimento das ações de controle de perdas nos sistemas de abastecimento de água.

\section{ANÁLISE DOS INDICADORES DE EFICIÊNCIA ENERGÉTICA DO SIAA TEODORO SAMPAIO/R1 DUNA}

Quanto à eficiência energética, em razão da peculiaridade de cada sistema de abastecimento de água, não foram comparados os dados entre sistemas distintos. Assim, levantaram-se dados secundários do SIAA Teodoro Sampaio/R1 Duna antes e após a realização do Convênio ECV-017/2004.

Com a Figura 5, observa-se que os dois indicadores analisados apresentaram redução depois da implementação das medidas para eficiência energética da unidade operacional, considerando as duas alternativas de funcionamento dos equipamentos (1 Conjunto Motor Bomba - CMB; ou 2 CMB em operação).

$\mathrm{Na}$ Figura 6 são comparadas as informações para o município de Salvador (SNIS, 2011), medições de campo realizadas para o projeto de eficiência da unidade operacional Parque da Federação

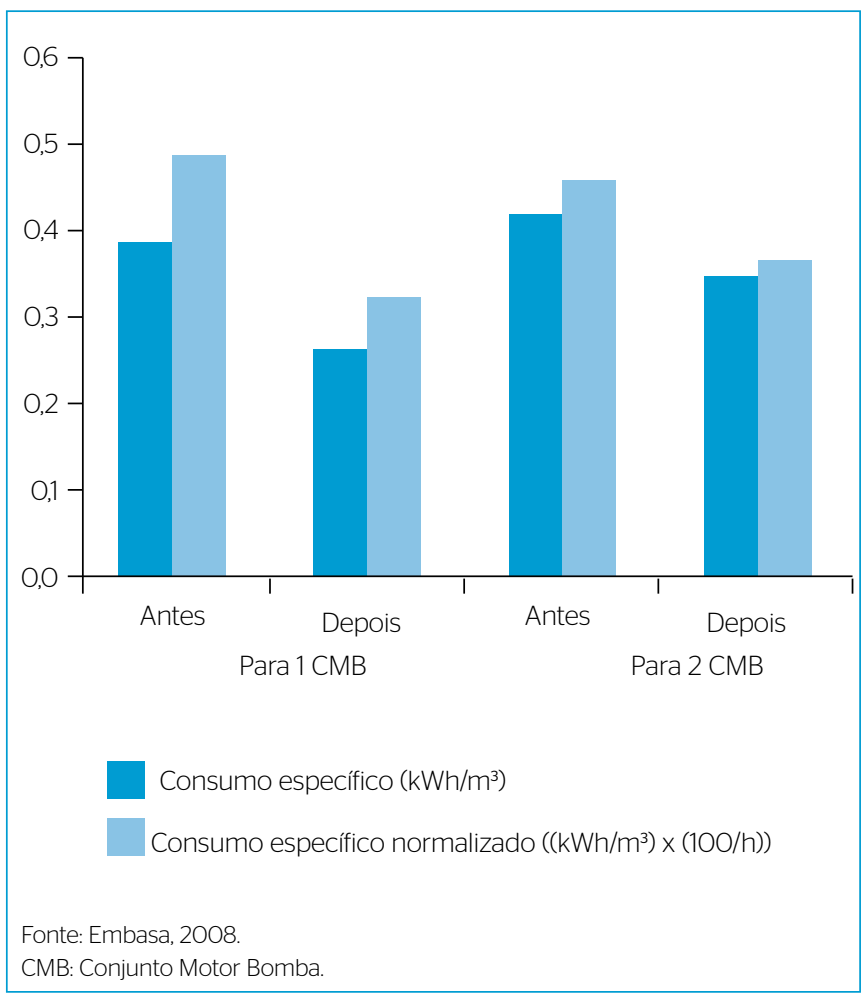

Figura 5 - Consumo específico e consumo específico normalizado para o sistema Estação Elevatória de Água Tratada Teodoro Sampaio/R1 Duna.
(R15) e também resultados indicados pelas referências bibliográficas consultadas.

Observou-se que o município de Salvador, onde está inserida a Estação Elevatória Água Tratada (EEAT) Teodoro Sampaio/R1 Duna, exibiu valores abaixo dos sugeridos por Tsutiya (2001). Esses dados justificam-se pelo fato de os sistemas de Salvador não possuírem grandes alturas manométricas e, portanto, não contarem com estações elevatórias em série. É comum em sistemas do interior do estado da Bahia, onde os mananciais estão distantes das sedes urbanas, existirem consumos específicos elevados, como, por exemplo, o sistema de SIAA Serrinha/Conceição do Coité, que demonstra indicadores de consumo específico em torno de 2 a $3 \mathrm{kWh} / \mathrm{m}^{3}$ (SNIS, 2011).

Os valores de referência de consumo específico sugeridos por Tsutiya (2001) retratam as características dos sistemas do Sudeste do Brasil, mais precisamente do estado de São Paulo. Considerando que as regiões brasileiras têm diferenciações topográficas e climáticas, esses valores devem ser usados com cautela. No caso da Embasa, há que se levar em conta que parte do território do estado da Bahia se localiza na região do semiárido, onde a distância dos mananciais para abastecimento dos principais núcleos urbanos é um fator a ser ressaltado, limitando o uso dos valores sugeridos por Tsutiya (2001). Por outro lado, no estado, é comum a implantação de SIAAs com grandes extensões, podendo atingir distâncias de recalque acima de $100 \mathrm{~km}$.

A despeito dessa questão, o SIAA Teodoro Sampaio/R1 Duna apresentou indicador de consumo específico compatível e satisfatório, devendo-se registrar as melhorias após as ações de eficiência energética realizadas por meio do Convênio ECV-017/2004.

A Figura 7 ilustra o desempenho do indicador em questão no SIAA Teodoro Sampaio/R1 Duna e aquele projetado para a unidade

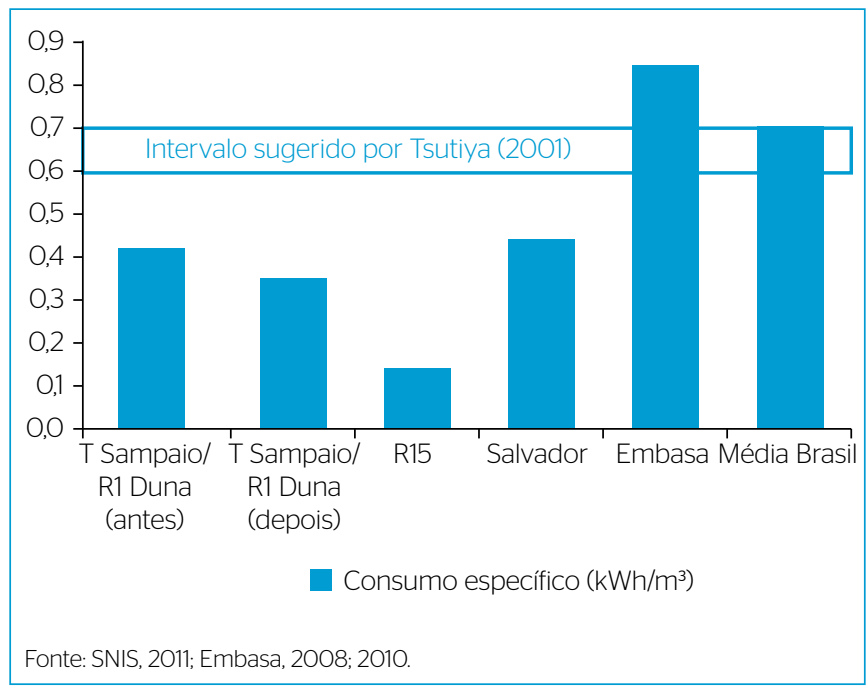

Figura 6 - Comparação entre consumos específicos. 


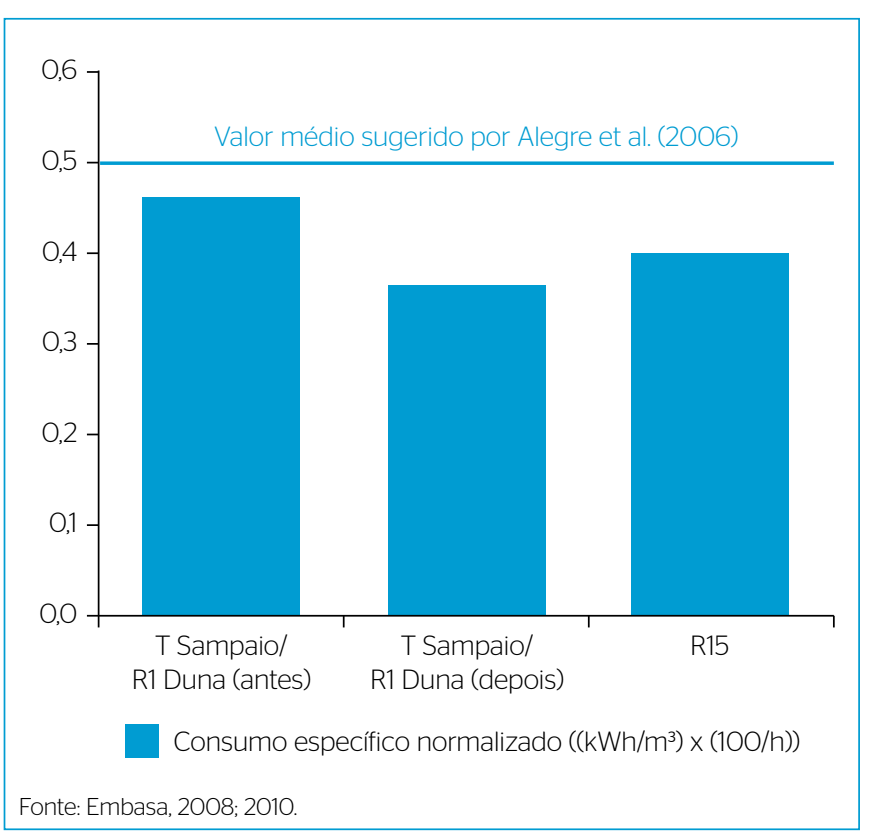

Figura 7 - Comparação entre consumos específicos normalizados. operacional Parque da Federação (R15). Observa-se que os indicadores se encontram abaixo do valor indicado por Alegre et al. (2006).

Vale observar que o indicador consumo específico normalizado apresenta bons resultados na área de estudo, pois praticamente inexistem estações elevatórias posicionadas em série, o que é muito comum para sistemas de abastecimento de água implantados no interior do estado da Bahia. No caso do SIAA Teodoro Sampaio/R1 Duna, antes da implementação do projeto de eficiência energética, esse indicador era de aproximadamente 0,48 , e depois passou a ser 0,38 . Houve, portanto, melhoria nos resultados (ANDRADE SOBRINHO, 2012).

Diante dos resultados do presente estudo e considerando a literatura, pôde-se identificar um conjunto de variáveis, organizadas em seis categorias de análise (fatores técnicos, operacionais, administrativos, gerenciais, ambientais e sociais), que se mostraram importantes para o desenvolvimento de ações para a gestão integrada de água e eficiência energética. A expectativa era a de que a problemática das perdas de água e energia fosse abordada na sua complexidade e intersetorialidade, superando dessa forma o tratamento segmentado, disciplinar e setorizado do fenômeno (Quadro 3).

Quadro 3 - Fatores intervenientes da gestão de perdas de água e eficiência energética.

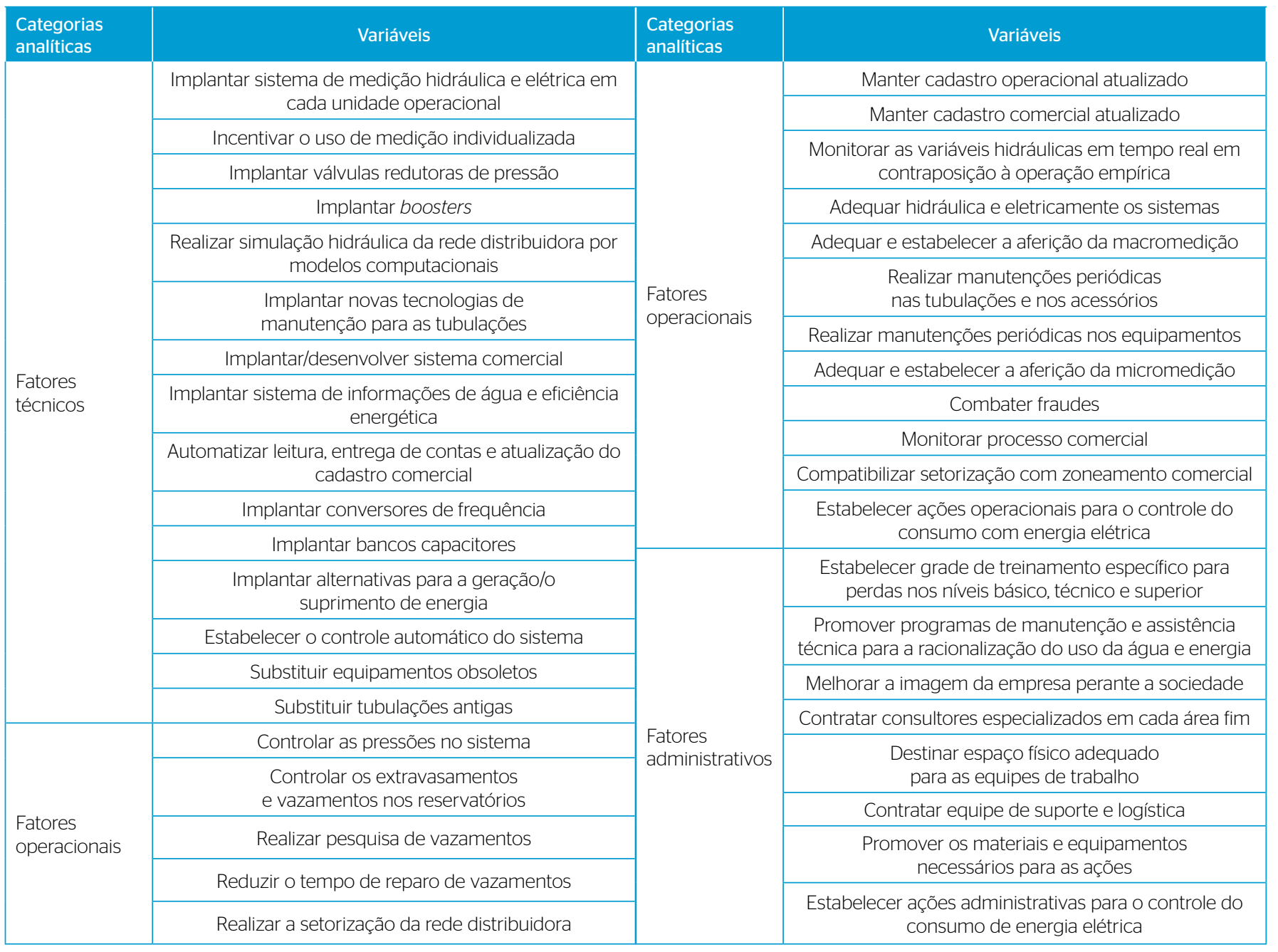


Quadro 3- Continuação.

\begin{tabular}{|c|c|c|c|}
\hline $\begin{array}{l}\text { Categorias } \\
\text { analiticas }\end{array}$ & Variáveis & $\begin{array}{l}\text { Categorias } \\
\text { analiticas }\end{array}$ & Variáveis \\
\hline \multirow{18}{*}{$\begin{array}{l}\text { Fatores } \\
\text { gerenciais }\end{array}$} & Buscar financiamentos para sistemas em operação & \multirow{7}{*}{$\begin{array}{l}\text { Fatores } \\
\text { gerenciais }\end{array}$} & Estabelecer política de combate às fraudes \\
\hline & Buscar financiamentos para novos sistemas & & Promover equipe de eficientização \\
\hline & Reduzir custos & & descentralizada, com gerente do processo com \\
\hline & \multirow{2}{*}{$\begin{array}{c}\text { Estabelecer política interna de perdas de água e } \\
\text { eficiência energética }\end{array}$} & & \\
\hline & & & Desenvolver estudos e programas \\
\hline & Propor e implementar as bases legais & & $\begin{array}{l}\text { de avallaçao ae novas tecnologlas para perdas } \\
\text { de água e eficiência energética }\end{array}$ \\
\hline & $\begin{array}{c}\text { Estabelecer objetivos e metas com o seu devido } \\
\text { acompanhamento, desdobrando-os para água e } \\
\text { eficiência energética }\end{array}$ & & $\begin{array}{l}\text { Promover gestão integrada e participativa com } \\
\text { estabelecimento de reuniões periódicas }\end{array}$ \\
\hline & Estabelecer reuniões periódicas & \multirow{4}{*}{$\begin{array}{l}\text { Fatores } \\
\text { ambientais }\end{array}$} & Reduzir retirada de água dos mananciais \\
\hline & Estabelecer protocolos de coleta e análise de dados & & Minimizar a geração de esgotos domésticos \\
\hline & Promover o gerenciamento da rede distribuidora & & Reduzir emissões atmosféricas \\
\hline & $\begin{array}{c}\text { Desenvolver parcerias com outras instituições na área } \\
\text { de perdas de água e eficiência energética }\end{array}$ & & $\begin{array}{l}\text { Promover o cumprimento da } \\
\text { legislação de recursos hídricos }\end{array}$ \\
\hline & $\begin{array}{c}\text { Desenvolver novos projetos focados nas ações de } \\
\text { perdas de água e eficiência energética }\end{array}$ & \multirow{7}{*}{ Fatores sociais } & Melhorar a qualidade de vida da população \\
\hline & & & Melhorar a saúde da população \\
\hline & desempenho para água e energia & & Promover programas de educação ambiental para uso \\
\hline & Promover contratos específicos de performance & & \\
\hline & Promover incentivos e recompensas à equipe & & $\begin{array}{l}\text { Estabelecer canais de comunicação } \\
\text { entre a empresa e os usuários }\end{array}$ \\
\hline & $\begin{array}{c}\text { Realizar planejamento (inclusive financeiro) } \\
\text { para ação contínua no controle de perdas de água e } \\
\text { eficiência energética }\end{array}$ & & $\begin{array}{l}\text { Diminuir a tarifa de água e esgoto por meio das } \\
\text { reduções de gastos com as ações de perdas de água e } \\
\text { eficiência energética }\end{array}$ \\
\hline & $\begin{array}{c}\text { Designar equipes específicas para atuação na área de } \\
\text { perdas de água e eficiência energética }\end{array}$ & & Gerar novos empregos \\
\hline
\end{tabular}

\section{CONCLUSÕES}

Embora a literatura forneça diversas estratégias e métodos para a gestão de forma integrada do uso eficiente da água e energia elétrica, no Brasil as ações dos prestadores de serviços públicos, com raras exceções, têm se caracterizado como pontuais, descontínuas e isoladas. Com isso, os níveis de perdas têm se mantido altos, em torno de 30 a 40\%, evidenciando a necessidade de identificar os limites e as possibilidades da implementação de programas que visem enfrentar essa problemática.

A Embasa, no período de 1996 a 2011, na RMS, promoveu alguns programas para o controle de perdas de água e eficiência energética. Após as análises desses programas, pôde-se observar que o planejamento e a execução das ações se caracterizaram, fundamentalmente, por uma abordagem dos aspectos técnicos/operacionais, quer seja de água, quer seja de eficiência energética. Os programas implantados caracterizaram-se como pontuais, com tempo determinado, sem contar com um planejamento mais sistêmico e estratégico, voltado para o desenvolvimento de atividades a curto, médio e longo prazos.

Os resultados da análise dos programas de perdas de água evidenciaram que logo após os processos de implementação ocorreram reduções nos indicadores avaliados, embora estes tenham se mantido em patamares altos. Observou-se que depois de um determinado período os indicadores voltaram a subir, evidenciando a necessidade de ações de caráter permanente, de modo a elevar o controle de perdas a uma ação estratégica e integrante das políticas dos prestadores de serviços.

Por outro lado, no programa de eficiência energética realizado na EEAT Teodoro Sampaio/R1 Duna se verificou que os resultados foram mais satisfatórios. O estabelecimento de indicadores e o acompanhamento de metas por parte do financiador do projeto podem ter contribuído para esse resultado. Neste projeto, constatou-se um esforço para o conhecimento prévio dos dados primários como cadastro, grandezas hidráulicas e elétricas, e, além disso, ocorreram discussões entre as partes interessadas para a sua implementação e internalização na empresa. O projeto desenvolvido para a eficiência energética .para a unidade operacional Parque da Federação (R15) seguiu a mesma direção, recebendo nacionalmente o prêmio de Gestão Eficiente de Energia Elétrica e Água, antes mesmo de serem implantadas as intervenções, em função do grau de detalhamento e confiabilidade das informações disponibilizadas.

Dessa forma, conclui-se que é necessária a atuação da alta direção da Embasa, não apenas com o intuito do estabelecimento e cobrança de metas, como também de capacitação de recursos humanos, 
disponibilidade de recursos e planejamento das ações, visando desenvolver um corpo técnico específico, preparado tecnicamente e capaz de coordenar e disseminar as ações na empresa.

Um dos desafios para os gestores que atuam no controle de perdas de água e eficiência energética é a necessidade de conhecer as tecnologias e metodologias existentes, com suas respectivas potencialidades e limitações, permitindo adequar e utilizar todos os recursos disponíveis de maneira a atingir seus objetivos e metas, com vistas a construir uma cultura efetiva por meio de medidas continuadas. Como consequência desse planejamento, podem-se obter resultados adequados a curto, médio e longo prazos, proporcionando mais eficiência, eficácia e efetividade da gestão dos sistemas de abastecimento de água e buscando garantir a sua sustentabilidade e a universalização dos serviços.
Faz-se fundamental desenvolver um conjunto de indicadores capazes de avaliar a eficácia, efetividade e eficiência das ações implementadas, o qual deve incorporar o tratamento mais integral da problemática do uso eficiente da água e energia. Outra questão relevante é a necessidade de mensurar a postergação de futuros investimentos com as ações de controle das perdas de água, considerando não só a minimização das perdas reais e aparentes, mas principalmente levando-se em conta a sustentabilidade de um sistema de abastecimento de água do ponto de vista econômico-financeiro, e sobretudo socioambiental.

O sucesso de políticas, programas, projetos e ações voltados para o uso eficiente da água e energia, obrigatoriamente, exige concepções voltadas para a intersetorialidade e integralidade das ações, bem como deve contar com a vontade política não só dos dirigentes, do corpo técnico, administrativo e gerencial, mas também da sociedade como um todo.

\section{REFERÊNCIAS}

ALEGRE, H.; BAPTISTA, J.M.; CABRERA JR., E.; CUBILLO, F.; DUARTE, P.; HIMER, W.; MERKEL, W.; PARENA, R. (2006) Performance indicators for water supply services. 2. ed. Londres: IWA. (IWA Manual of Best Practice Series.)

ANDRADE SOBRINHO, R. (2012) Gestão das perdas de água e energia em sistema de abastecimento de água da Embasa: um estudo dos fatores intervenientes na RMS. 178 f. Dissertação (Mestrado em Meio Ambiente, Águas e Saneamento)-Universidade Federal da Bahia, Salvador.

ALLIANCE TO SAVE ENERGY - ASE. (2002) Watergy: taking advantage of untapped energy and water efficiency opportunities in municipal water systems. Washington: Alliance to Save Energy.

ALLIANCE TO SAVE ENERGY - ASE. (2007) Watergy: energy and water efficiency in municipal water supply and wastewater treatment - cost-effective savings of water and energy. Washington: Alliance to Save Energy.

AMERICAN WATER WORKS ASSOCIATION - AWWA. (1999) Energy and water management system. Denver: American Water Works Association Research Foundation.

BAGGIO, M.A. (2000) Diagnóstico de perdas de sistemas de abastecimento de água. Franca: ABES.

BRASIL. Ministério das Cidades. Secretaria Nacional de Saneamento Ambiental. (2008) Abastecimento de água: gerenciamento de perdas de água e energia elétrica em sistemas de abastecimento. Guia do profissional em treinamento: nível 2. Salvador: ReCESA. 139 p.

CENTRAIS ELÉTRICAS BRASILEIRAS - ELETROBRAS. (2005) Plano de ação Procel Sanear 2006/2007. Brasília: Eletrobras.
CHEUNG, P.B.; KIPERSTOK, A.; COHIM, E.; ALVES, W. C.; PHILIPPI, L.S.; ZANELLA, L.; ABE, N.; GOMES, H.P.; SILVA, B.C.; PERTEL, M.; GONÇALVES, R.F. (2009) Consumo de água. In: GONÇALVES, R.F. (Org.) Conservação de água e energia em sistemas prediais e públicos de abastecimento de água. Rio de Janeiro: ABES. p. 36-98.

EMPRESA BAIANA DE ÁGUAS E SANEAMENTO - EMBASA. (1999) Diagnóstico global operacional / comercial e planejamento, controle e supervisão da implantação de três distritos operacionais de controle de perdas no S. I. A. A. de Salvador, Lauro de Freitas e Simões Filho. Relatório Final. Salvador: Embasa. Não publicado.

EMPRESA BAIANA DE ÁGUAS E SANEAMENTO - EMBASA. (2008) Relatório mensal de despesas com energia elétrica. Salvador: Embasa. Não publicado.

EMPRESA BAIANA DE AGUAS E SANEAMENTO - EMBASA. (2010) Relatório mensal de despesas com energia elétrica. Salvador: Embasa. Não publicado.

EMPRESA BAIANA DE ÁGUAS E SANEAMENTO - EMBASA. (2O11) Relatório mensal de despesas com energia elétrica. Salvador: Embasa. Não publicado.

EMPRESA BAIANA DE ÁGUAS E SANEAMENTO - EMBASA. (2012) Relatório do controle operacional de água e esgoto. Salvador Copae/Embasa. Não publicado.

GOMES, H.P.; CHEUNG, P.B.; SILVA, B.C.; BEZERRA, S.T.M. (2009) Tecnologias de Conservação em Sistemas Públicos. In: Gonçalves, R.F. (Coord.) Uso racional de água e energia. Projeto PROSAB Capítulo 4. Rio de Janeiro: ABES. p. 153-218.

IONESCU, G.C. (2004) The optimization of the hydraulic installations within the water supply systems. Bucareste: Matrix Rom. 
ITONAGA, L.C.H. (2005) Estudo da aplicação de modelos de redes de água no controle de perdas em casos reais. 201 f. Dissertação (Mestrado em Tecnologia Ambiental e Recursos Hídricos) Universidade de Brasília, Brasília.

MAGALHÃES, A.S. (2001) Metodologia para diagnóstico e controle de perdas: uma experiência desenvolvida em sistema de abastecimento de água. Salvador: Embasa.

MARCKA, I.; CONEJO, J.G.L.; SILVA, R.T. (2004) Indicadores de perdas nos sistemas de abastecimento de água. Documento Técnico de Apoio - DTA A2. Brasília: Ministério das Cidades/SNSA/PNCDA.

MARQUES, M.C.S.; HADDAD, J.; GUARDIA, E.C. (2007) Eficiência energética: teoria \& prática. Itajubá: Fupai.

MIRANDA, E.C. (2002) Avaliação de perdas em sistemas de abastecimento de água: indicadores de perdas e metodologias para análise de confiabilidade. 193 f. Dissertação (Mestrado em Tecnologia Ambiental e Recursos Hídricos) - Universidade de Brasília, Brasília.
ORMSBEE, L.E.; WALKI, J.M. (1989) Identifying efficient pump combinations. Journal American Water Works Association, v. 81, n. 1, p. 30-34.

SISTEMA NACIONAL DE INFORMAÇÕES SOBRE SANEAMENTO SNIS. (2011) Diagnóstico dos Serviços de Água e Esgoto. Brasília: Ministério das Cidades/SNSA/PMSS.

TSUTIYA, M.T. (2001) Redução do custo de energia elétrica em sistemas de abastecimento de água. São Paulo: ABES. 185 p.

TSUTIYA, M.T. (2004) Abastecimento de água. São Paulo: ABES. 634 p.

UNITED NATIONS HUMAN SETTLEMENTS PROGRAMME - UNHABITAT. (2011) Annual report 2010. United Nations Human Settlements Programme. Nairóbi, Quênia.

WERDINE, D. (2002) Perdas de água em sistemas de abastecimento. 129f. Dissertação (Mestrado) - Universidade de Itajubá, Itajubá. 